\title{
TIPOLOGIAS DE PRODUTORES E COMPONENTES DOS SISTEMAS DE PRODUÇÃO IDENTIFICADOS NA COMUNIDADE AÇAIZAL, MONTE ALEGRE, PARÁ
}

\author{
Sandy Santos da Fonseca'; Roberta Rowsy Amorim de Castro². \\ ${ }^{1}$ Universidade Federal do Pará, Altamira, Pará, Brasil, sandysandyze@gmail.com \\ 2 Universidade Federal do Pará, Abaetetuba, Pará, Brasil, roberta_rowsy@hotmail.com
}

RESUMO: Este artigo objetivou identificar e caracterizar as tipologias de produtores e os componentes dos sistemas de produção desenvolvidos nas unidades produtivas da Comunidade Açaizal, localizada no município de Monte Alegre, estado do Pará. Trabalhou-se com um universo amostral de 33 famílias, deste participaram do estudo 21 famílias. Para o levantamento da diversidade de tipologias utilizou-se de formulário semiestruturado. Identificou-se seis (6) tipos de unidades de produção, sendo cinco (5) familiares e uma patronal, algumas destas subdivididas em tipos específicos. Nas unidades familiares predomina a mão de obra familiar, a pequena propriedade e a diversificação de sistemas de produção conforme o tamanho dos lotes. Os sistemas de produção operados por essas famílias são de cultivos de ciclo curto como milho (Zea mays L.), feijão caupi (Vigna unguiculata (L.) Walp.), arroz (Oriza sativa), mandioca (Manihot esculenta Crantz.) e perenes como pastagens, sistemas de criação de animais como bovinos, aves e suínos e sistema extrativista representado pelas áreas de mata primária e mata ciliar. Com relação às unidades patronais, predomina a criação extensiva de bovinos de corte, mão de obra contratada e mecanização do solo na formação de pastagens. O trabalho aponta para a elaboração de estratégias de acordo com as especificidades das tipologias identificadas, visando à perpetuação das atividades, a reprodução social, melhoria das técnicas de cultivos, criações e manejo do solo.

PALAVRAS-CHAVE: Agricultura Familiar, Sistema de Produção, Unidade Produtiva.

\section{TYPOLOGIES OF PRODUCERS AND COMPONENTS OF THE PRODUCTION SYSTEMS IDENTIFIED IN THE AÇAIZAL COMMUNITY, MONTE ALEGRE, PARÁ}

ABSTRACT: This article aimed to identify and characterize the types of producers and to identify the components of production systems developed in the production units of the Açaizal community, located in the municipality of Monte Alegre, in the state of Pará. The sample universe is 33 families, 21 families participated in the study. In order 
to survey the diversity of typologies, a semi-structured form was used and observations were made on the socioeconomic conditions, the relationship with the land, the crops and creations, income and the workforce in the locality. Six types of production units were identified: five family members and one employer, some of these subdivided into specific types. In family units, family labor, small ownership and diversification of production systems are predominant, depending on the size of the lots. The production systems operated by these families are of annual crops such as maize (Zea mays L.), cowpea (Vigna unguiculata (L.) Walp.), rice (Oriza sativa), crops such as manioc (Manihot esculenta Crantz.), and perennials such as pastures, breeding systems such as cattle, poultry and pigs, and the extractive system represented by primary forest and ciliary forest. With regard to the units, the extensive creation of beef cattle, hired labor and mechanization of the soil in the formation of pastures predominates. The work aims at the elaboration of strategies adjusted to the specificities of the typologies identified, aiming at the perpetuation of activities, social reproduction, improvement of crop techniques, creations and soil management.

KEYWORDS: Family Farming, Production System, Productive Unit.

\section{TIPOLOGÍAS DE PRODUCTORES Y COMPONENTES DE LOS SISTEMAS DE PRODUCCIÓN IDENTIFICADOS EN LA COMUNIDAD AÇAIZAL, MONTE ALEGRE, PARÁ}

RESUMEN: Este artículo objetivó identificar y caracterizar las tipologías de productores y los componentes de los sistemas de producción desarrollados en las unidades productivas de la Comunidad Açaizal, ubicada en el municipio de Monte Alegre, estado de Pará. Se trabajó con un universo muestral de 33 familias, participaron del estudio 21 familias. Para el levantamiento de la diversidad de tipologías se utilizó de formulario semiestructurado. Se identificaron seis (6) tipos de unidades de producción, siendo cinco (5) familiares y una patronal, algunas de ellas subdivididas en tipos específicos. En las unidades familiares predomina la mano de obra familiar, la pequeña propiedad y la diversificación de sistemas de producción según el tamaño de los lotes. Los sistemas de producción operados por esas familias son de cultivos de ciclo corto como maíz (Zea mays L.), frijol caupi (Vigna unguiculata (L.) Walp.), Arroz (Oriza sativa), mandioca (Manihot esculenta Crantz.) Y. perennes como pastos, sistemas de cría de animales como bovinos, aves y cerdos y sistema extractivista representado por las áreas de mata primaria y mata ciliar. Con respecto a las unidades patronal, predomina la cría extensiva de bovinos de corte, mano de obra contratada y mecanización del suelo en la formación de pastos. El trabajo apunta a la elaboración de estrategias de acuerdo con las especificidades de las tipologías identificadas, 
visando la perpetuación de las actividades, la reproducción social, la mejora de las técnicas de cultivos, creaciones y manejo del suelo.

PALABRAS CLAVE: Agricultura Familiar, Sistema de Producción, Unidad Productiva.

O estado do Pará tem excelente potencial produtivo, despertando também uma preocupação maior com a sustentabilidade das atividades estabelecidas nos agroecossistemas (RODRIGUES et al., 2012). Para conciliar o desenvolvimento econômico dos sistemas produtivos com a veia de preservação dos recursos naturais é preciso, segundo Maia e Riedl (2017), criar estratégias para que as comunidades participem da elaboração das políticas públicas, o que de acordo com Ploeg (2014) eleva o grau de resiliência econômica, ecológica e social das comunidades rurais.

Segundo Porto (2003) a elaboração de programas, sejam eles de origem regional ou local, passa primeiramente pelo conhecimento das demandas do espaço rural e estudos sobre as tipologias de produtores e a identificação dos componentes dos sistemas de produção, é importante, pois irá demonstrar a organização das categorias de produtores e quais são os sistemas de produção desenvolvidos, permitindo com isso uma aproximação dos principais gargalos e reflexões acerca de sugestões aplicáveis a realidade no intuito de amenizar os efeitos negativos desses gargalos.

Porto (2003) reflete ainda que a caracterização e identificação dos diferentes tipos de produtores e de sistemas de produção ajuda na compreensão da sua lógica de funcionamento e com mais riqueza de detalhes, as inter e intra-relações presentes na estrutura agrária.

Garcia Filho (1996) esclarece que não existe uma tipologia padrão para ser seguida, pois é a realidade encontrada que determinará a melhor abordagem para agrupar os produtores. No entanto, o mesmo 
afirma que na maior parte dos estudos da Organização das Nações Unidas para a Alimentação e a Agricultura ONU/FAO são encontrados três de tipos de unidades de produção: as unidades capitalistas, as unidades familiares e as unidades patronais. As unidades capitalistas são expressas por grandes áreas, onde os proprietários não trabalham diretamente na produção, mas administra sua propriedade por meio de trabalhadores rurais mediante pagamento de salários. As unidades familiares são caracterizadas pelo domínio do trabalho familiar no lote em detrimento do trabalho remunerado e nas unidades patronais os proprietários participam do processo produtivo podendo dispor de trabalhadores assalariados em tempo integral ou não.

Nesse contexto, o objetivo deste trabalho foi identificar e caracterizar as tipologias de produtores e os componentes dos sistemas de produção desenvolvidos nas unidades produtivas da Comunidade Açaizal, localizada no município de Monte Alegre, no estado do Pará.

O trabalho foi realizado no município de Monte Alegre, situado à margem esquerda do rio Amazonas, na mesorregião do Baixo Amazonas, onde faz limite ao norte com o município de Almeirim, ao leste com Almeirim e Prainha, ao sul com Prainha e Santarém e a oeste com o município de Alenquer (SEPOF, 2012).

De acordo com o censo demográfico realizado no ano de 2010 pelo Instituto Brasileiro de Geografia e Estatística, a população é de aproximadamente 55.462 habitantes, sendo que a população rural é maior que a população urbana (IBGE, 2017), dessa maneira torna-se de fundamental importância estudos sobre esse vasto universo rural, buscando agregar conhecimentos e fortalecer a agricultura como um todo. A escolha da Comunidade Açaizal como objeto de estudo, zona rural do município de Monte Alegre, se deu de modo a contribuir e disseminar a riqueza de conhecimentos presentes 
na localidade, sendo o ponto inicial de acesso à comunidade a Rodovia Estadual PA-425.

O universo amostral da Comunidade Açaizal é de 33 famílias e deste total participaram da pesquisa 21 famílias, o que, em termos percentuais, corresponde a $64 \%$ da população. As principais dificuldades vivenciadas durante a coleta de informações em campo foram relacionadas a transporte e as longas distâncias entre as propriedades, sendo assim necessário recorrer ao uso de motocicleta e caminhadas.

Para a elaboração das tipologias de produtores e dos componentes dos sistemas de produção ${ }^{1}$ utilizou-se os dados obtidos por meio de formulário aplicado no mês de junho de 2015, a partir de hospedagem de 15 dias em residência de agricultor. No formulário as questões foram elaboradas conforme a leitura de Garcia Filho (1996), por isso o esforço no sentido de

\footnotetext{
1 Sistema de produção em uma unidade produtiva é a combinação das atividades produtivas e dos seus meios de produção para
}

identificar e caracterizar as tipologias de produtores pela lógica de funcionamento, itinerários técnicos adotados, tipos de cultivos e criações, identificação das atividades que geram renda e a mão de obra predominante nas propriedades.

A Comunidade Açaizal tem uma população de 33 famílias, que se reconhecem como agricultoras e têm como principal fonte de renda os cultivos de ciclo curto com a mandioca, transformando este tubérculo em farinha comercializada ao longo do ano. Além disso, identificaram-se outras atividades desenvolvidas nas unidades produtivas tais como cultivos anuais e criações de animais de grande porte (bovinos e equinos), médio porte (suínos) e pequeno porte (aves) e atividades extrativistas como o processamento artesanal dos frutos de açaí (Euterpe oleracea Mart.) para consumo na forma de sucos. As atividades desenvolvidas nas unidades

\footnotetext{
a obtenção de recursos explorados no ecossistema (GARCIA FILHO, 1996; MAZOYER; ROUDART, 2010).
} 
produtivas, com exceção da criação de animais de grande porte, são voltadas mais para o autoconsumo do que para a comercialização.

A Comunidade Açaizal é constituída pela faixa de terras abertas que se estende por cerca de 8 quilômetros (Rodovia Estadual PA-425), trecho este denominado Açaizal e por dois ramais, que foram surgindo devido ao crescimento populacional e a necessidade de exploração de novas áreas e deram origem a duas outras sub-regiões: o Ramal Igarapé do Meio e o Ramal Paxiúba.

Em 2010 a energia elétrica chegou à Comunidade por meio do Programa Luz para Todos (ELETROBRAS, 2017) do Governo Federal, e atualmente, devido à ausência de cadastro nas Centrais Elétricas do Pará, apenas uma família não goza dos benefícios que a energia elétrica proporciona como acesso a televisão, bombeamento de água para as dependências das casas, refrigerador para armazenamento de carnes, polpas e bebidas entre outros trunfos.
Constatou-se, durante 0 levantamento de dados, que os agricultores ainda não despertaram para o uso de cultivos irrigados nos sistemas produtivos para suprir as necessidades das plantas nos períodos de seca, mantendo-se fieis ao calendário agrícola regulado pelas chuvas.

Com relação à situação fundiária, verificou-se por meio dos informantes e de posterior consulta ao Instituto Nacional de Colonização e Reforma Agrária (INCRA), que as terras habitadas pelas famílias na localidade Açaizal pertencem ao Instituto de Terras do Pará (ITERPA), sendo que os agricultores detêm apenas a posse da terra. Esta limitação ocasionada pela ausência de título do imóvel rural dificulta o pleiteamento de crédito rural junto às instituições financeiras.

Dentre as unidades produtivas amostradas ocorrem seis tipos de produtores, sendo cinco familiares e um patronal, alguns destes subdivididos em tipos específicos conforme representação na Tabela 1. 
Tabela 1. Tipologia de produtores identificada na Comunidade Açaizal, Monte Alegre, PA. *Para não ocorrer duplicação na frequência, consideraram-se os agricultores familiares assalariados empregados como contabilizados na unidade patronal onde residem com a família. ${ }^{* *}$ As letras maiúsculas da coluna Localização correspondem: A-Açaizal; I M- Igarapé do Meio; I PIgarapé Paxiúba.

\begin{tabular}{|c|c|c|c|}
\hline \multicolumn{4}{|c|}{ Tipologias de produtores na comunidade Açaizal } \\
\hline Tipos & Subtipos & Frequência & Localização*ᄎ \\
\hline \multirow{2}{*}{$\begin{array}{l}\text { 1- Agricultor familiar de cultivos de } \\
\text { ciclo curto }\end{array}$} & Áreas até 3 ha & 8 & IP \\
\hline & Áreas até 50 ha & 1 & $\mathrm{IM}$ \\
\hline \multirow{2}{*}{$\begin{array}{l}\text { 2- Agricultor familiar aposentado + } \\
\text { cultivos de ciclo curto + criação } \\
\text { bovina de gado de corte }\end{array}$} & $\begin{array}{c}\text { Criação até } 5 \text { cabeças } \\
\text { bovinas }\end{array}$ & 2 & $\left|M_{;}\right| \mathrm{P}$ \\
\hline & Criação até 65 cabeças & 4 & $\mathrm{~A}$ \\
\hline \multirow[b]{2}{*}{ 3- Agricultor familiar assalariado } & Posse da terra & 1 & $I P$ \\
\hline & $\begin{array}{l}\text { Empregados na terra } \\
\text { somente }\end{array}$ & * & $A_{;} \mid M$ \\
\hline \multirow{2}{*}{$\begin{array}{l}\text { 4- Agricultor familiar de cultivos de } \\
\text { ciclo curto + aluguel de pastagem }\end{array}$} & Terra firme & 1 & $\mathrm{~A}$ \\
\hline & Várzea & 1 & $\mathrm{~A}$ \\
\hline $\begin{array}{l}\text { 5- Agricultor familiar de cultivos de } \\
\text { ciclo curto + criação bovina }\end{array}$ & Sem subtipos & 1 & $\mathrm{IM}$ \\
\hline \multirow{3}{*}{ 6-Produtores patronais } & Criação de peixes & 1 & $\mathrm{~A}$ \\
\hline & Criação de gado de corte & 1 & $\mathrm{IM}$ \\
\hline & Total & 21 & \\
\hline
\end{tabular}

Dentre os tipos representados na Tabela 1, o de maior ocorrência é atribuído aos agricultores familiares de cultivos de ciclo curto que residem em unidades produtivas de até 3 hectares, localizadas no ramal Igarapé Paxiúba e aqueles que residem em unidades de até 50 hectares. As famílias reunidas neste grupo operam com mão de obra predominantemente familiar, atividades de plantios anuais ou de ciclo curto como as culturas de milho, feijão caupi e arroz, destinados ao consumo no lote e cultivos como a mandioca e a macaxeira, destinados à produção de farinha para a venda e para o consumo. A farinha de mandioca é de suma importância por ser a principal fonte de renda, 
necessária para suprir as demandas do lote e dos membros das famílias.

É característica dos agricultores familiares de cultivos de ciclo curto a pouca disponibilidade de terras agricultáveis para exploração em virtude das unidades produtivas não ultrapassarem 3 hectares, tal condição interfere no tamanho dos roçados ${ }^{2}$, restringindo-os a pequenas áreas cultivadas de 50 metros $\times 50$ metros em média, por isso é comum a associação dessas famílias a outras da Comunidade para trabalhar nos roçados como estratégia para aumentar a produção e consequentemente a renda. No entanto, a mesma situação não ocorre nas unidades de até 50 hectares, o que reflete diretamente no tamanho dos roçados, que neste caso são em média 70 metros $\times 70$ metros.

O segundo tipo mais frequentemente identificado foi o de agricultor familiar aposentado + cultivos de ciclo curto + criação bovina de corte (Tabela 1), esta dividida entre dois subtipos que se diferenciam pela criação de até 5 cabeças de bovinos ou até 65 cabeças de bovinos. Ela reúne agricultores aposentados que ainda desenvolvem atividades complementares a aposentadoria, tais como cultivos anuais para consumo e a criação de bovinos para venda em casos de emergência. Os agricultores deste grupo enfrentam a deficiência de mão de obra, pois a maioria dos filhos (as) não reside na unidade produtiva com os pais. Para compensar essa carência eles lançam mão de estratégias como arrendamento de pastagens, venda de animais anualmente para pagamento de despesas e diárias advindas das atividades no lote, além de cederem áreas agricultáveis para que outros agricultores da Comunidade possam implantar roçados, onde a produção

\footnotetext{
2 Roçados são como os agricultores da Comunidade Açaizal denominam as áreas destinadas aos plantios.
} 
obtida é geralmente dividida em partes iguais.

Segundo Finatto e Salamoni (2008) quando o agricultor recorre a outros agricultores para auxílio em atividades que demandem mão de obra como, por exemplo, plantio ou colheita, priorizam geralmente aos laços de parentesco ou aos vizinhos mais próximos, configurando uma característica bastante presente na agricultura familiar que é a ajuda mútua, isto porque é uma relação desprovida da noção de capital, e esse tipo de relação ocorre na Comunidade Açaizal, gerando trocas benéficas entre os agricultores que precisam de mão de obra para operar seus sistemas de cultivos e os agricultores que vivem a escassez de terras agricultáveis.

O tipo agricultor familiar assalariado é o terceiro de maior frequência, reúne um grupo de agricultores assalariados, por trabalhos como agente comunitário de saúde ou vaqueiro, ambos representam a principal fonte provedora de renda de suas famílias. Neste grupo, existem dois subtipos principais, sendo o primeiro constituído por agricultores que têm atividade remunerada e são donos da unidade produtiva onde residem, e o segundo subtipo é constituído por agricultores que são assalariados, porém não são os donos da unidade produtiva. Segundo Schneider (2003) essas atividades consideradas extra lote, podem ou não estar ligadas à agricultura e são denominadas de pluriatividades, sendo possível serem compreendidas como estratégias de reprodução social e econômica.

O quarto tipo identificado em Açaizal é o agricultor familiar de cultivos de ciclo curto + aluguel de pastagem que apresenta as mesmas características das tipificações anteriores de cultivos de ciclo curto, acrescida da atividade aluguel de pastagem, esta última ocorre na localidade sob dois subtipos distintos. O primeiro contempla o arrendamento da pastagem em pequenas quadras para o rebanho de vizinhos ou para agricultores de outras comunidades em períodos onde a propriedade do 
dono do rebanho apresenta baixa oferta de alimento, conferindo ao arrendador uma renda extra. E O segundo subtipo contempla agricultores que pagam o aluguel de pastagens durante alguns meses na várzea ${ }^{3}$ visando o descanso, formação e limpeza de seus pastos para receber novamente o plantel.

O quinto tipo, identificado no ramal Igarapé do Meio, é o agricultor familiar de cultivos de ciclo curto + criação bovina, que reúne características como cultivos anuais (milho, arroz e feijão caupi) para consumo e o beneficiamento das raízes de mandioca para fabricação de farinha destinada ao consumo e a venda, além da criação média de 15 cabeças de bovinos destinados à venda anual. A unidade produtiva apresenta tamanho médio de 30 hectares. As dimensões médias dos roçados são de 70 metros x 70 metros.

\footnotetext{
${ }^{3}$ Várzea é o local onde ocorrem inundações anuais das terras promovidas pelas cheias dos rios, alguns agricultores costumam levar o rebanho para a várzea quando as águas dos rios estão com baixa vazão para que a pastagem da terra firme se recupere e possa
}

O último tipo apresenta características semelhantes ao tipo fazendeiro capitalista, identificado por Simões et al. (2011) isso porque os proprietários não residem e não trabalham no lote, fazendo uso de trabalhadores assalariados. A tomada de decisões diárias da propriedade fica sob a responsabilidade do funcionário e a tomada de decisões acerca do futuro e o acompanhamento do funcionamento das atividades a cargo dos proprietários. Devido a essas características, as unidades produtivas desse tipo, conforme Garcia Filho (1996) foram classificadas como unidades patronais.

Em virtude das principais atividades desenvolvidas nas unidades patronais estas foram divididas em dois subtipos: criação de peixes e criação de gado de corte. No primeiro, os produtores desenvolvem a criação de peixes apenas para o consumo por meio de

novamente receber os animais. O retorno do rebanho para a terra firme inicia-se geralmente no mês de janeiro quando as chuvas se intensificam na região e as águas dos rios começam a crescer e alagar as áreas de pastagens naturais. 
trabalhador assalariado, responsável pelo manejo e alimentação dos animais na unidade. Desta forma, a exploração do lote visa a sua manutenção, sendo mantida por meio de fontes remuneradas externas do produtor.

Já o subtipo unidade patronal de criação de bovinos de corte ocorre em grandes extensões de pastagens em regime extensivo, dispondo de instalações como cochos e currais de madeira. As demandas anuais com vacinações dos bovinos, alimentação complementar, implantação e manutenção de pastagens, gastos com remédios, insumos, ferramentas, pagamento de funcionários, diaristas, entre outros, são sanadas com a venda de cabeças de gado, que se constitui como a principal fonte de renda.

Apesar das unidades familiares da Comunidade Açaizal possuírem características distintas, descritas por meio das tipologias, verificou-se que existem pontos importantes que as reúnem e ajudam na sua compreensão, tais como: emprego da mão de obra familiar operando os sistemas de cultivo de ciclo curto, a gestão das decisões acerca do futuro da unidade, a pequena propriedade, produção de farinha, os programas sociais e o autoconsumo.

Na divisão dos afazeres, com uso da mão de obra familiar, os filhos ajudam os pais nas atividades de capinas, colheitas, plantios, roços e, em alguns casos, a rebanhar o gado. As filhas participam ajudando nas atividades da mãe que incluem cozinhar, zelar pela limpeza da casa e alimentar pequenos animais. Em certas ocasiões, como no beneficiamento da mandioca para produção de farinha, é preciso utilizarse de toda a força de trabalho disponível, dessa forma os membros da família atuam em conjunto para a geração do bem que beneficiará a todos.

A gestão da tomada de decisões referente à unidade produtiva é compartilhada pelos casais. $\bigcirc$ homem atua como força de trabalho mais intensa dentro dos sistemas operados pela família, tendo a esposa como sua auxiliar e os filhos (as) como 
aprendizes, corroborando-se com Melo (2002) ao refletir que o trabalho da mulher na agricultura é considerado "ajuda", isso porque é o homem quem domina as etapas de produção, o que reafirma a existência da divisão de trabalho entre os sexos e o não reconhecimento do trabalho da mulher na unidade produtiva.

A diversificação de produtos produzidos nas unidades familiares da Comunidade Açaizal está relacionada ao tamanho dos lotes, visto que unidades pequenas concentram atividades em roçados pequenos, produzem menos e desenvolvem até dois sistemas, como no caso do subtipo agricultores familiares de cultivos de ciclo curto com áreas até 3 hectares. Além disso, assim como foi verificado por Costa et al. (2014), em áreas menores o uso do solo é intenso, e na Comunidade Açaizal são os agricultores familiares de áreas até 3 hectares que vivenciam essa realidade, utilizando o máximo possível da área do lote para manterem-se atuantes no meio rural.
Por outro lado, os agricultores familiares conseguem diversificar suas atividades quando residem em unidades produtivas maiores, a exemplo dos agricultores do ramal Igarapé do Meio que ocupam áreas médias de 23,7 hectares e de Açaizal que ocupam áreas médias de 41,63 hectares. Esses agricultores produzem grãos, farinha, carne, e alguns realizam até mesmo o arrendamento de pastagens, corroborando-se com Alves (2011) que destaca que a diversificação dos sistemas de produção depende dos fatores de produção que as famílias dispõem como áreas agricultáveis, recursos financeiros, condição dos solos e a mão de obra para trabalhar na unidade de produção.

É também uma característica marcante das unidades produtivas familiares da Comunidade o autoconsumo, que segundo Grisa et al. (2010) engloba o cultivo de alimentos, de animais, confecção de ferramentas e a produção de insumos utilizados no processo produtivo, e no caso dos 
agricultores deste estudo é um ponto positivo para a economia de recursos com alimentação e melhor aproveitamento dos recursos financeiros.

Os programas assistenciais do Governo Federal se fazem presentes para os agricultores familiares com o Bolsa Família, visto que $48 \%$ das famílias pesquisadas têm filhos (as) que recebem o auxílio. Os valores pecuniários ajudam a elevar a renda e a qualidade de vida das pessoas, sendo que em média cada família recebe por mês cerca de $R \$ 300,00$.

Além disso, 17 casais são associados ao Sindicato de Trabalhadores e Trabalhadoras Rurais (STTR) do município de Monte Alegre, segundo os mesmos é importante a filiação ao sindicato para manter-se atualizado a respeito dos interesses da classe à qual pertencem, e para receber apoio no gozo da aposentadoria e de auxílio maternidade.

Por outro lado, nas unidades patronais encontra-se uma realidade oposta a das unidades familiares, pois são propriedades caracterizadas por médias e grandes extensões de terra, mão de obra assalariada e concentração em apenas um tipo de atividade rural, a respeito disso, a análise dos dados comparando as atividades dos agricultores familiares com as atividades dos produtores patronais permite inferir que estes geralmente são mais capitalizados. As pistas levantadas para justificar tais ocorrências são confirmadas por Simões et al. (2011) que verificaram que produtores capitalizados possuem as maiores áreas e os descapitalizados menores áreas e predomínio de mão de obra familiar.

Segundo Guilhoto et al. (2007) a agricultura familiar no Brasil tem grande importância, mesmo enfrentando uma série de dificuldades para produzir como a insuficiência de terras, capital, financiamentos junto a órgãos bancários, baixo nível tecnológico e de assistência técnica. Tais dificuldades contribuem para que as unidades patronais, devido à maior capitalização e a maior disponibilidade 
de terras, tenham melhor econômicos na natureza e na aproveitamento dos recursos e sociedade onde ela está inserida.

retornos financeiros advindos das A realização da categorização das atividades que exercem.

tipologias de produtores contribuiu

Para Ploeg (2014) é preciso que a para identificar os componentes dos agricultura nas unidades familiares sistemas de produção, estes trilhe um caminho que aprimore o representados na Tabela 2 em: sistema estilo de vida camponês tanto de produção quanto de vida, em de cultivos de ciclo curto, sistema de cultivos permanentes, sistema detrimento ao estilo empresarial típico extrativista, sistema de criação de das unidades patronais, a partir do desenvolvimento de agroecossistemas animais de grande porte e sistema de criação de animais pequenos.

pautados em princípios ecológicos e

Tabela 2. Componentes dos Sistemas de Produção identificados na Comunidade Açaizal, Monte Alegre, PA.

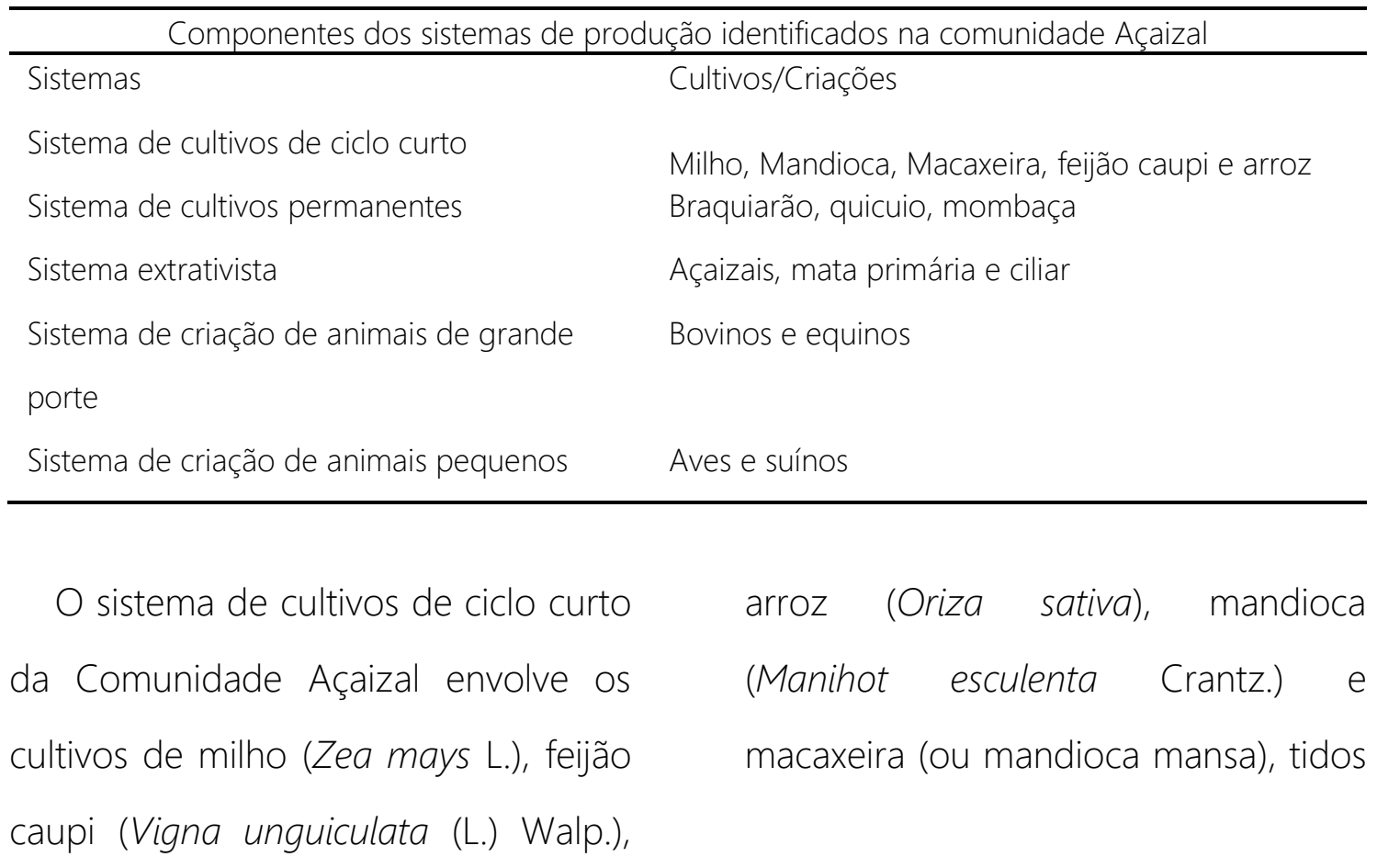


pelos agricultores como essenciais para a subsistência das famílias.

No sistema de cultivo permanente estão as forrageiras braquiarão (Brachiaria brizantha), quicuio (Brachiaria humidicola) e mombaça (Panicum maximum), estas são presentes nas unidades patronais de criação de gado de corte e nas unidades familiares que trabalham com a criação de bovinos ou o aluguel de pastagens.

O sistema extrativista é formado por pequenas áreas de açaizais nativos, mata primária e mata ciliar encontrada ao longo do curso dos igarapés, cuja formação vegetal destaca-se a espécie florestal nativa pau mulato ou mulateiro (Calycophyllum spruceanum).

No sistema de criação de animais de grande porte estão os bovinos (Bos taurus), que representam a principal atividade das unidades patronais, e os equinos (Equus caballus). O emprego dos equinos nas unidades produtivas é de grande importância nos períodos em que o gado é levado para a várzea, nos trabalhos diários com o rebanho e como meio de transporte.

Segundo Tosseto et al. (2013) os animais ruminantes são essenciais nos sistemas de produção em função da produção de esterco que ajuda na reposição natural de nutrientes no solo, fornecimento de carne, banha e leite que é a matéria prima para fabricação de outros produtos, além da complementação da força de trabalho e transporte na execução de serviços do cotidiano rural, tais contribuiç̧ões também estão presentes nos sistemas produtivos da Comunidade Açaizal.

De maneira geral, os bovinos na Comunidade Açaizal são manejados no sistema de produção de cria-recriaengorda e no sistema de criação de animais pequenos as aves e suínos são criados em regime extensivo, ou seja, soltos nas áreas dos quintais agroflorestais e são fontes de proteínas da alimentação familiar em praticamente todos os lotes.

O preparo do solo nos sistemas de cultivos, com exceção das unidades patronais, é operado na mesma lógica 
em todas as unidades familiares antes da implantação de qualquer espécie, e as áreas utilizadas no preparo do solo para os cultivos não ultrapassam um hectare, sendo de 0,25 ha nas propriedades do Igarapé Paxiúba e 0,50 ha nas propriedades de Açaizal e Igarapé do Meio. A retirada da vegetação se dá pelo sistema de corte e queima (Figura 1) exigindo grande esforço físico dos agricultores, especialmente entre os meses de novembro e/ou dezembro, considerando o calendário agrícola local.

Figura 1. Etapas de preparo do solo realizadas para implantação de cultivos nas unidades familiares da Comunidade Açaizal, Monte Alegre, PA.

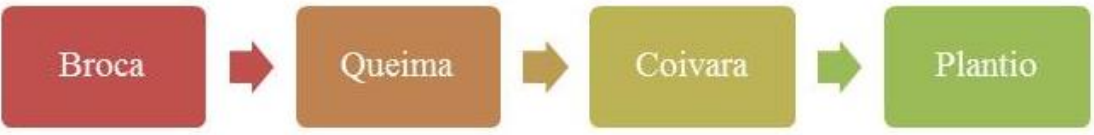

A broca é realizada com o auxílio de ferramentas como facões, foices, motosserras e machados, e por ser bastante penosa é feita pelos homens, consistindo em um roço rústico visando à derrubada da vegetação. Segundo Rodrigues et al. (2012) é preciso um esforço no sentido de buscar alternativas de baixo impacto e que podem substituir essa e outras práticas do sistema corte e queima, como, por exemplo, a roça-sem-queima.
Sobre as queimadas há relatos de que já aconteceu de o fogo fugir ao controle e se espalhar rapidamente invadindo propriedades vizinhas ou áreas de açaizais nativos, mesmo os agricultores alegando que são adeptos do uso de aceiros.

A coivara representa uma etapa de grande importância, pois é onde ocorre o aproveitamento de galhos e/ou troncos para lenha. As principais ferramentas empregadas para reduzir e 
facilitar o transporte das madeiras para as casas são motosserras e machados, usados para garantir cortes de tamanhos menores, tornando mais fácil o deslocamento.

As peças de madeiras cortadas permanecem na área de preparo do solo ou são transportadas para as dependências das casas dos agricultores ou para as casas de farinha, onde ficam armazenadas aguardando o momento oportuno para que sejam utilizadas como lenha. As cinzas restantes na área queimada, segundo os agricultores, ajudam no desenvolvimento das plantas, como um adubo natural rico em nutrientes.

Com a área limpa e as chuvas começando entre novembro, dezembro e intensificando-se no mês de janeiro, os agricultores aguardam por dias chuvosos para que as sementes tenham condições de umidade suficientes para a germinação.

Segundo Schmitz (2007) é comum o emprego do sistema corte e queima pela agricultura familiar na Amazônia, onde durante o período de 1-3 anos realiza-se plantios anuais para a alimentação e logo após a área é deixada em pousio para que haja formação de capoeira e recuperação da fertilidade do solo, a esse tipo de agricultura, presente em Açaizal, o autor denomina de agricultura itinerante.

A respeito do sistema de pousio, adotado pelos agricultores na Comunidade, verificou-se que o intervalo é de 3 a 4 anos, sendo de 3 anos em unidades produtivas menores. Alves (2011) constatou em seu estudo na Comunidade denominada de Nossa Senhora de Lourdes (estado do Pará) que a redução no intervalo de pousio afeta negativamente o processo de ciclagem e fertilidade do solo, a autora identificou que durante anos as famílias de agricultores trabalharam no sistema de corte e queima com pousios de 6 a 8 anos, porém com o desaparecimento de áreas de mata e capoeira grossa o tempo de pousio foi reduzido para 2 anos, e tais condições fizeram com que os agricultores adotassem a queima e emprego de adubos e defensivos 
químicos para compensar a baixa eficiência das áreas agricultáveis.

O preparo do solo envolvendo a broca, a queima, coivara e o plantio, bem como as capinas é geralmente realizado por homens (pais e filhos) nas unidades familiares da Comunidade Açaizal por serem considerados trabalhos árduos, e as esposas e filhas, além do trabalho em atividades domésticas, atuam em atividades tidas como "mais leves" como a colheita dos cultivos e algumas etapas da produção de farinha, porém, dependendo da condição e disponibilidade de mão de obra no lote, as mulheres executam as etapas de produção dos cultivos e criações, corroborando com Melo (2002) na assertiva de atribuições entre o trabalho masculino tido como penoso e o feminino tido como leve no preparo para plantios e manejo de animais de grande porte. Todavia, na análise dos resultados também se pode apoiar em Alves (2011), pois esta destaca que a condição de cada grupo na divisão social do trabalho é moldada pelas situações vivenciadas no dia a dia da unidade de produção, e isso também ocorre na Comunidade estudada.

Por meio do estudo verificou-se que as tipologias de produtores e a análise e descrição dos componentes dos sistemas de produção evidenciaram que a Comunidade Açaizal é dominada por unidades familiares pequenas, uso da mão de obra familiar, prática da agricultura itinerante, repasse de saberes tradicionais sobre cultivos e criações, aproveitamento o máximo dos solos por meio de consórcios e rotações culturais e autoconsumo.

Entretanto, existem especificidades na tipologia de produtores que evidenciaram tipos e subtipos de agricultores familiares, sendo mais frequente o subtipo agricultores familiares de cultivos de ciclo curto (áreas até 3 ha), onde o maior gargalo enfrentado pelos agricultores é o tamanho da propriedade, que por ser pequena é explorada intensamente afetando diretamente o sistema de pousio e reposição de nutrientes no solo. Uma das alternativas a serem pensadas e construídas junto aos 
agricultores deste grupo é a diversificação de atividades por meio da implantação de sistemas agroflorestais com arranjos produtivos baseados na preferência do mercado consumidor local e a implantação de hortaliças no sistema de plantio irrigado visto que ambas ocupam poucos hectares, e, além disso, a Comunidade fica próxima da cidade e conta com energia elétrica.

Ademais, considerando que praticamente todos os tipos e subtipos de agricultores familiares tem experiência com os cultivos de ciclo curto, é interessante a adoção por parte destes, de princípios baseados na agroecologia, na adubação orgânica e no aprimoramento dos sistemas de rotação e consórcios culturais visando à conservação da fertilidade do solo para os próximos cultivos.

Para os tipos que englobam os agricultores familiares que trabalham com a criação bovina, independentemente de serem aposentados ou não, e para os agricultores que alugam pastagens uma boa alternativa seria a adoção do sistema silvipastoril, que combina o manejo do pasto com árvores e gado em uma mesma área. As interações que ocorrem em áreas que tem 0 sistema silvipastoril proporcionam principalmente a diversificação da produção por meio do plantio de árvores frutíferas ou de interesse florestal, o conforto térmico dos bovinos nas horas mais quentes do dia e ganhos ambientais como o aumento da área de cobertura vegetal na unidade produtiva.

O tipo agricultor familiar assalariado é o que requer atenção especial, em virtude da fragilidade econômica dos agricultores, evidenciada na sua reprodução social visto que possíveis cortes de renda salarial comprometeriam sua sobrevivência, por isso a adoção de sistemas agroflorestais e o cultivo de hortaliças são estratégias que poderiam atuar na complementação da renda deste grupo.

Por fim, todos esses apontamentos e até mesmo outras propostas de desenvolvimento para a localidade envolvem primeiramente a 
apresentação deste estudo para as famílias da Comunidade Açaizal no intuito de confirmar ou reelaborar as tipologias de produtores, e em um segundo momento a construção de ideias individuais e coletivas que contemplem principalmente seus anseios, afinidades produtivas e as características das tipologias, o que demanda um processo de discussão e planejamento participativo, sendo de fundamental importância o apoio dos órgãos do município ligados à agricultura, em um processo democrático e socialmente construído.

\section{REFERÊNCIAS}

ALVES, K. S. Organização do trabalho de famílias agricultoras na comunidade Nossa Senhora de Lourdes, Nordeste Paraense. 115 f. Dissertação (Mestrado em Agriculturas Familiares e Desenvolvimento Sustentável). Universidade Federal do Pará, Belém, 2011.

COSTA, Z. F.; JOCOSKI, L. V.B.; HERSEN, A.; STEFANO, S. R.; RAMOS, R. P. Características socioeconômicas da agricultura familiar produtora de milho: um estudo de caso dos produtores Pinhão-PR. Revista do Setor de Ciências
Agrárias e Ambientais, v. 10, n. 3, p. 807828, 2014.

ELETROBRAS. Centrais Elétricas Brasileiras S.A. Luz para Todos. Disponível em: < http://eletrobras.com/pt/Paginas/Luzpara-Todos.aspx>. Acesso em: 28 out. 2017.

FINATTO, R. A.; SALAMONI, G. Agricultura familiar e agroecologia: perfil da produção de base agroecológica do município de Pelotas/RS. Revista Sociedade \& Natureza, v. 20, n. 2, p. 199-217, 2008.

GARCIA FILHO, D. P. Análise Diagnóstico de Sistemas Agrários: guia metodológico, INCRA/FAO. Projeto UFT/BRA/051/BRA. Agosto de 1996.

GRISA, C.; GAZOLLA, M.; SCHNEIDER, S. A "produção invisível" na agricultura familiar: autoconsumo, segurança alimentar e políticas públicas de desenvolvimento rural. Revista Agroalimentaria, v. 16, n. 31, p. 65-79, 2010.

GUILHOTO, J. J. M.; ICHIHARA, S. M.; SILVEIRA, F. G.; DINIZ, B. P. C.; AZZONI, C. R.; MOREIRA, G. R. C. A Importância da Agricultura Familiar no Brasil e em seus Estados. Brasília: NEAD, 2007.

IBGE. Censo Demográfico, 2010. Disponível em <www.ibge.gov.br> Acesso em: 15 mar. 2017.

MAIA, C. M.; RIEDL, M.; Agricultura e dinâmicas do desenvolvimento rural no contexto da globalização. Revista do 
Desenvolvimento Regional, v. 14, n. 1, p. 169-191, 2017.

MAZOYER, R.; ROUDART, L. História das agriculturas no mundo: do neolítico à crise contemporânea (Tradução de FALLUH, C.F.; FERREIRA, B.). São Paulo: Editora UNESP. Brasília, DF: NEAD, 2010. $568 p$.

MELO, L. A. Injustiças de gênero: o trabalho da mulher na agricultura familiar, 2002. In: ENCONTRO DA ASSOCIAÇÃO BRASILEIRA DE ESTUDOS POPULACIONAIS, 13. Anais... Minas Gerais: Fundação Joaquim Nabuco, 2002.

PLOEG, J. D. V. D. As dez qualidades da agricultura familiar. Revista Agriculturas: experiências em agroecologia, Cadernos de debate n. 1. Rio de Janeiro: AS-PTA, 2014.

PORTO, V. H. F. sistemas agrários: uma revisão conceitual e de métodos de identificação como estratégias para o delineamento de políticas públicas. Revista Cadernos de Ciência \& Tecnologia, Brasília, v. 20, n.1, p. 97-121, 2003.

RODRIGUES, D. M.; SILVA, M. M.; ALMEIDA, L. S.; SOUZA, J. T. R.; YARED, J. A. G.; SANTANA, A. C. Agrobiodiversidade e os serviços ambientais: perspectivas para o manejo ecológico dos agroecossistemas no estado do Pará. Revista Agroecossistemas, v. 4, n. 1, p. 12-32, 2012.
SCHMITZ, H. A transição da agricultura itinerante na Amazônia para novos sistemas. Revista Brasileira de Agroecologia, v. 2, n. 1, p. 46-49. 2007.

SCHNEIDER, S. Teoria social, agricultura familiar e pluriatividade. Revista Brasileira de Ciências Sociais, v. 18, n. 51, p. 99-121, 2003.

Secretaria de Estado de Planejamento, Orçamento e Finanças - SEPOF. Estatística Municipal, Monte Alegre, Pará. Disponível em: < http://seicom.pa.gov.br/kitminera cao/estatistica-municipal/regiao-dobaixo amazonas/MonteAlegre.pdf >. Acesso em: 12 jul. 2017.

SIMÕES, H. M.; PIRES, M.; M.; GOMES, A. S. Análise-diagnóstico de Sistema Agrário em uma perspectiva socioeconômica e ambiental. Revista Brasileira de Gestão e Desenvolvimento Regional, v. 7, n. 2, p. 182-204, 2011.

TOSSETO, E. M.; CARDOSO, I. M.; FURTADO, S. D. C. A importância dos animais nas propriedades familiares rurais agroecológicas. Revista Brasileira de Agroecologia, v.8, n.3, p. 12-25, 2013. 